\title{
SITC.N
}

KONKURENTNOST

TURISTIČKE DESTINACIJE

TOURISM

DESTINATION COMPETITIVENESS

DOI: $10.15308 /$ sitcon-2015-122-126

\section{ODRŽIVA STOPA RASTA HOTELSKIH I UGOSTITELJSKIH PREDUZEĆA U SRBIJI}

\author{
Zoran Jović ${ }^{1}$, Kosana Vićentijević ${ }^{2}$, Zoran Petrović ${ }^{2}$ \\ ${ }^{1}$ Univerzitet Singidunum, Poslovni fakultet u Valjevu, Železnička 5, Valjevo, Srbija \\ ${ }^{2}$ Univerzitet Singidunum, Beograd, Danijelova 32, Srbija
}

\begin{abstract}
Apstrakt:
Sva profitabilna preduzeća, a među njima i hotelska i ugostiteljska preduzeća, mogu doći u finansijske teškoće pa čak i bankrotstvo ukoliko rastu sporije ili brže nego što je to optimalno. Ocena presporog ili prebrzog rasta hotelskih i ugostiteljskih preduzeća postiže se upoređivanjem sa njihovom održivom stopom rasta. Sama održiva stopa rasta predstavlja maksimalnu stopu rasta koju jedno preduzeće može ostvariti bez dodatnog zaduživanja. Cilj ovog istraživanja jeste da se utvrdi održiva stopa rasta za pojedina hotelska i ugostiteljska preduzeća u Srbiji u 2012. i 2013. godini i da se utvrdi da li postoje razlike između ovog sektora i drugih privrednih sektora u Srbiji po ovom pitanju. Pored toga, istraživanje nastoji da utvrdi i realnu održivu stopu rasta hotelskih i ugostiteljskih preduzeća u Srbiji uzimanjem u obzir aktuelne stope inflacije u posmatranim godinama, kao i da pojasni uzroke neslaganja između nominalnih i realnih održivih stopa rasta. Realne održive stope rasta analiziranih hotelskih i ugostiteljskih preduzeća u Srbiji služe kao orijentir u donošenju zaključka o razvojnom potencijalu ovih preduzeća i oslonac u pronalaženju adekvatnih internih i eksternih podsticaja za dalji potencijalni rast ovih preduzeća.
\end{abstract}

\author{
Ključne reči: \\ održiva stopa rasta, \\ hotelska i ugostiteljska preduzeća, \\ dividendna politika.
}

\section{UVOD}

Održiva stopa rasta (SGR - sustainable growth rate) jednog preduzeća predstavlja maksimalnu stopu rasta koju to preduzeće može da ostvari bez dodatnog zaduživanja. Ukoliko jedno hotelsko ili ugostiteljsko preduzeće raste po nižoj stopi od održive stope rasta to ga može dovesti do stagnacije i gubitka konkurentske pozicije, što u dužem vremenskom periodu može rezultirati i bankrotstvom takvog preduzeća. Takođe, ako jedno hotelsko ili ugostiteljsko preduzeće raste prebrzo, odnosno ukoliko raste po stopi koja je viša od održive stope rasta, to ga može dovesti do finansijskih problema uzrokovanih prezadužavanjem, do nelikvidnosti, a u krajnjem slučaju, u dužem vremenskom periodu, taj proces takođe može voditi preduzeće ka bankrotstvu. Načini finansiranja ubrzanog rasta hotelskih i ugostiteljskih preduzeća mogu biti dvostruki, odnosno interni i eksterni. Interno, ova preduzeća mogu povećavati efikasnost svog poslovanja, ubrzavati obrt ukupne imovine i svih njenih pojedinačnih delova, a eksterno se mogu, $s$ jedne strane, oslanjati na povećanje zaduženosti, ili s druge strane, na dokapitalizaciju putem dodatne emisije akcija.

Neobuzdani rast može da bude u suprotnosti sa finansijskom politikom preduzeća (Higgins, 1997). Ukoliko povećanje prodaje ide preko održive stope rasta, to preduzeće uvodi u finansijske probleme jer zahteva nova zaduživanja za finansiranje ubrzanog rasta. Povećanje prodaje hotelskih i ugostiteljskih preduzeća može biti rezultat povećanog obima pruženih usluga ili rezultat povećanja cena usluga. Zbog toga je neophodno razmotriti i uticaj inflacije na održivu stopu rasta (Higgins, 1981). Važan zadatak vlasnika i menadžera hotelskih i ugostiteljskih preduzeća je utvrđivanje održive stope rasta. Utvrđivanje SGR je utvrđivanje najviše stope rasta koju preduzeće može da održi bez povećanja svog finansijskog leveridža (Brealey \& Myers, 2003). Model održivog rasta predstavlja efikasno sredstvo za finansijsko planiranje i usmeravanje poslovne politike ka stimulaciji rasta u pojedinim privrednim granama (Clouse \& McFaddin, 1994). Utvrđivanjem odnosa između investicione odluke o optimalnom rastu i politike isplate dividendi proširen je $\mathrm{Hi}$ ginsov model održivog rasta modelom koji optimizuje održivu stopu rasta i racio isplate dividendi (Chen et al., 2013).

U istraživanju su korišćene osnovne naučne metode analize i sinteze, indukcije i dedukcije, metoda komparacije, statističke metode i hipotetičko-deduktivne metode. Za prikupljanje podataka korišćena je metoda analize sadržaja dokumenata.

U fokusu ovog istraživanja su profitabilna hotelska i ugostiteljska preduzeća iz Srbije, jer samo preduzeća sa pozitivnim finansijskim rezultatom, tj. preduzeća koja ostvaruju dobit, mogu ostvariti i određenu održivu stopu rasta. Analizirano je 8 hotelskih i ugostiteljskih preduzeća čijim 
akcijama se trguje na Beogradskoj berzi. Pažnja je usmerena na hotelska i ugostiteljska preduzeća jer zahvaljujući svojim prirodnim predispozicijama i geografskom položaju Srbije, turizam, hotelijerstvo i ugostiteljstvo imaju značajan razvojni potencijal u Srbiji. Otuda i interesovanje autora istraživanja za analizu održive stope rasta hotelskih i ugostiteljskih preduzeća u Srbiji. U istraživanje je uključena i prerađivačka industrija u Srbiji kao kontrolni sektor nezavisan od hotelskog i ugostiteljskog sektora, kako bi rezultati hotelskih i ugostiteljskih preduzeća mogli biti upoređeni sa rezultatima drugih grana. Istraživanjem je izvršena komparativna analiza održive stope rasta hotelskih i ugostiteljskih preduzeća i prerađivačkih preduzeća za 2012. i 2013. godinu. Takođe, analiziran je odnos između održive stope rasta ovih preduzeća i stope inflacije u posmatranim godinama sa ciljem da se utvrdi da li postoji realni potencijal rasta analiziranih hotelskih i ugostiteljskih preduzeća.

U istraživanju se polazi od sledećih predloženih hipoteza:

H1: Ne postoji značajna razlika između održive stope rasta hotelskih i ugostiteljskih preduzeća i prerađivačkih preduzeća.

H2: Ne postoji značajna razlika između održive stope rasta hotelskih, ugostiteljskih i prerađivačkih preduzeća u 2013. godini u odnosu na 2012. godinu.

H3: Ne postoji značajna razlika između održive stope rasta i stope inflacije u 2012. godini.

H4: Ne postoji značajna razlika između održive stope rasta i stope inflacije u 2013. godini.

\section{ODREĐIVANJE ODRŽIVE STOPE RASTA HOTELSKIH I UGOSTITELJSKIH PREDUZEĆA U SRBIJI}

Za utvrđivanje održive stope rasta koristi se formula:

$$
\mathrm{g}=\mathrm{b} \times \mathrm{ROE}
$$

pri čemu g označava održivu stopu rasta; b označava racio dobiti koji nije isplaćen kroz dividende, tzv. retention rate, odnosno deo dobiti koji ostaje u preduzeću za dalji razvoj; ROE - return on equity odnosno stopa prinosa na sopstveni kapital ili popularno: profitna stopa.

U postupku izračunavanja održive stope rasta, ROE se primenom DuPont analize razlaže na sledeće komponente: profitnu maržu, racio obrta poslovne imovine i multiplikator sopstvenog kapitala (Stowe, 2000).

Prema prethodno utvrđenoj metodologiji izračunate su održive stope rasta (g) za 8 uzorkovanih hotelskih i ugostiteljskih preduzeća u 2012. i 2013. godini, a rezultati su prikazani u tabelama 1 i 2.

Može se uočiti da je dividendna politika analiziranih hotelskih i ugostiteljskih preduzeća u obe posmatrane godine nepromenjena i ujednačena. Naime nijedno posmatrano preduzeće nije isplaćivalo dividende iz ostvarene dobiti u obe godine, odnosno sva dobit je reinvestirana. Zbog toga je i retention racio (b) jednak jedinici za sva preduzeća u obe godine, što nije uobičajeno za preduzeća iz drugih privrednih

Tabela 1. Održive stope rasta uzorkovanih hotelskih i ugostiteljskih preduzeća u 2012. godini

\begin{tabular}{|c|c|c|c|c|c|c|}
\hline \multirow[t]{2}{*}{ Preduzeće } & $\mathrm{b}$ & ROE & Profitna marža & $\begin{array}{c}\text { Racio obrta } \\
\text { ukupne imovine }\end{array}$ & $\begin{array}{c}\text { Multiplikator } \\
\text { sopstvenog } \\
\text { kapitala }\end{array}$ & g \\
\hline & $(1)$ & $(2)=\left(3^{\star} 4^{\star} 5\right)$ & (3) & $(4)$ & (5) & $(6)=\left(1^{\star} 2\right)$ \\
\hline Astoria, Beograd & 1,00 & 0,14 & 0,42 & 0,29 & 1,14 & 0,14 \\
\hline Excelsior, Beograd & 1,00 & 0,70 & 2,68 & 0,17 & 1,56 & 0,70 \\
\hline Palisad, Zlatibor & 1,00 & 2,29 & 1,14 & 0,62 & 3,25 & 2,29 \\
\hline Tisa, Senta & 1,00 & 0,15 & 0,91 & 0,13 & 1,23 & 0,15 \\
\hline Avala, Požarevac & 1,00 & 38,08 & 66,28 & 0,34 & 1,70 & 38,08 \\
\hline Golubački grad, Golub. & 1,00 & 1,22 & 3,80 & 0,22 & 1,47 & 1,22 \\
\hline Madera, Beograd & 1,00 & 4,78 & 4,72 & 0,97 & 1,05 & 4,78 \\
\hline Pomoravlje, Beograd & 1.00 & 1,15 & 75,87 & 0,01 & 1,05 & 1,15 \\
\hline
\end{tabular}

Izvor: Prikaz autora na osnovu podataka iz www.belex.rs

Tabela 2. Održive stope rasta uzorkovanih hotelskih i ugostiteljskih preduzeća u 2013. godini

\begin{tabular}{|c|c|c|c|c|c|c|}
\hline Preduzeće & $\mathrm{b}$ & ROE & Profitna marža & $\begin{array}{c}\text { Racio obrta } \\
\text { ukupne imovine }\end{array}$ & $\begin{array}{c}\text { Multiplikator } \\
\text { sopstvenog } \\
\text { kapitala }\end{array}$ & g \\
\hline & $(1)$ & $(2)=\left(3^{\star} 4^{\star} 5\right)$ & (3) & (4) & (5) & $(6)=\left(1^{\star} 2\right)$ \\
\hline Astoria, Beograd & 1,00 & 2,47 & 7,18 & 0,31 & 1,12 & 2,47 \\
\hline Excelsior, Beograd & 1,00 & 3,75 & 15,06 & 0,16 & 1,59 & 3,75 \\
\hline Palisad, Zlatibor & 1,00 & 0,19 & 0,12 & 0,30 & 5,25 & 0,19 \\
\hline Tisa, Senta & 1,00 & 2,79 & 12,06 & 0,20 & 1,18 & 2,79 \\
\hline Avala, Požarevac & 1,00 & 17,77 & 23,31 & 0,48 & 1,58 & 17,77 \\
\hline Golubački grad, Golub. & 1,00 & 1,83 & 4,01 & 0,27 & 1,70 & 1,83 \\
\hline Madera, Beograd & 1,00 & 2,98 & 3,58 & 0,79 & 1,05 & 2,98 \\
\hline Pomoravlje, Beograd & 1,00 & 0,03 & 3,23 & 0,01 & 1,07 & 0,03 \\
\hline
\end{tabular}

Izvor: Prikaz autora na osnovu podataka iz www.belex.rs 
grana. Neisplaćivanje dividendi iz ostvarene dobiti pozitivno utiče na visinu održive stope rasta, ali zbog niske profitne stope preduzeća iz ove privredne grane, krajnji rezultat koji se u uslovima kada je retention racio jednak 1 izjednačava sa profitnom stopom, je takođe skoman. Značajnu održivu stopu rasta u obe godine je imalo samo preduzeće Avala iz Požarevca (38,08\% u 2012. godini i 17,77\% u 2013. godini). Skromnu održivu stopu rasta su imala preduzeća Madera iz Beograda (4,78\%) i Palisad sa Zlatibora (2,29\%) u 2012. godini i Excelsior iz Beograda (3,75\%), Madera (2,98\%), Tisa iz Sente (2,79\%) i Astoria iz Beograda (2,47\%) u 2013. godini. Ostala posmatrana preduzeća su imala gotovo zanemarivu održivu stopu rasta u obe analizirane godine.

Da bi se hotelska i ugostiteljska preduzeća uporedila sa preduzećima iz drugih industrijskih grana, $u$ analizu su uključena različita preduzeća iz prerađivačke industrije, takođe njih 8 u 2012. i 2013. godini (tabele 3 i 4). Uočljiva je razlika u dividendnoj politici ovih preduzeća u odnosu na hotelska i ugostiteljska preduzeća. Polovina ovih preduzeća (4 od 8) je u 2012. godini isplaćivalo dividende, a u 2013. godini čak 5 od 8 preduzeća je isplaćivalo dividende, što se vidi po retention raciju (b) koji je manji od 1 . No i pored toga održive stope rasta (g) preduzeća prerađivačke industrije su u obe posmatrane godine na znatno višem nivou nego kod hotelskih i ugostiteljskih preduzeća. Razlog tome je i znatno viša profitna stopa prerađivačkih preduzeća kao proizvoda profitne marže, racia obrta ukupne imovine i multiplikatora sopstvenog kapitala. Otuda se može zaključiti i da hotelska i ugostiteljska preduzeća pripadaju nisko profitabilnoj privrednoj grani u Srbiji i da sama, oslanjajući se na sopstvenu održivu stopu rasta ne mogu napraviti bitan razvojni pomak, bez pomoći i intervencije spolja, bilo kroz eksterni priliv kapitala, bilo kroz osmišljenu državnu intervenciju i pomoć u oblasti kreiranja povoljnih načina finansiranja.

Da bi se ustanovila realna vrednost izračunatih održivih stopa rasta hotelskih i ugostiteljskih preduzeća, kao i prerađivačkih preduzeća u 2012. i 2013. godini, u analizu u tabelama 5 i 6 je uključena i stopa inflacije koja je merena indeksom potrošačkih cena i koja je iznosila 12,2\% u 2012. godini i 2,2\% u 2013. godini (Ministarstvo finansija, 2014). Pošto je stopa inflacije u 2012. godini imala značajan nivo od $12,2 \%$, ispostavilo se da je samo jedno posmatrano hotelsko preduzeće u toj godini imalo pozitivnu realnu održivu stopu rasta, odnosno da je posedovalo realni potencijal za rast od 25,88\% (Avala, Požarevac). Sva ostala posmatrana preduzeća iz ovog sektora ostvarila su negativnu realnu održivu stopu rasta, tj. njihova ostvarena nominalna održiva stopa rasta je bila niža od stope inflacije, odnosno ova preduzeća nisu imala realni potencijal za samostalni održivi rast u 2012. godini. U 2013. godini, situacija je znatno drugačija, ne zbog bolje održive stope rasta ovih preduzeća, već zbog niske stope inflacije od samo 2,2\%, što je uslovilo da 5 posmatranih preduzeća ostvare pozitivnu realnu održivu stopu rasta, a samo 3, veoma nisku negativnu realnu održivu stopu rasta, odnosno da je za većinu ovih preduzeća postojao realni potencijal za samostalni rast u 2013. godini.

Tabela 3. Održive stope rasta uzorkovanih prerađivačkih preduzeća u 2012. godini

\begin{tabular}{|c|c|c|c|c|c|c|}
\hline \multirow[t]{2}{*}{ Preduzeće } & $\mathrm{b}$ & $\mathrm{ROE}$ & $\begin{array}{l}\text { Profitna } \\
\text { marža }\end{array}$ & $\begin{array}{c}\text { Racio obrta } \\
\text { ukupne imovine }\end{array}$ & $\begin{array}{l}\text { Multiplikator } \\
\text { sopstvenog } \\
\text { kapitala }\end{array}$ & g \\
\hline & $(1)$ & $(2)=\left(3^{\star} 4^{\star} 5\right)$ & (3) & (4) & (5) & $(6)=(1 \star 2)$ \\
\hline Alfa plam, Vranje & 1,00 & 20,53 & 25,54 & 0,66 & 1,21 & 20,53 \\
\hline Bambi, Požarevac & 0,80 & 25,87 & 13,48 & 0,98 & 1,95 & 20,70 \\
\hline Goša FOM, Smed. Palanka & 1,00 & 3,52 & 1,90 & 0,73 & 2,53 & 3,52 \\
\hline Imlek, Beograd & 0,83 & 25,21 & 13,12 & 0,86 & 2,24 & 20,92 \\
\hline Impol Seval, Sevojno & 0,93 & 16,08 & 3,59 & 1,31 & 3,42 & 14,95 \\
\hline Milan Blagojević, Smederevo & 1,00 & 36,08 & 19,40 & 1,12 & 1,66 & 36,08 \\
\hline Neoplanta, Novi Sad & 1,00 & 8,84 & 5,96 & 0,89 & 1,67 & 8,84 \\
\hline Žitobanat, Vršac & 0,52 & 8,17 & 3,17 & 1,60 & 1,61 & 4,25 \\
\hline
\end{tabular}

Izvor: Prikaz autora na osnovu podataka iz www.belex.rs

Tabela 4. Održive stope rasta uzorkovanih prerađivačkih preduzeća u 2013. godini

\begin{tabular}{lcccccc}
\hline \multirow{2}{*}{\multicolumn{1}{c}{ Preduzeće }} & $\mathrm{b}$ & ROE & Profitna marža & $\begin{array}{c}\text { Racio obrta uku- } \\
\text { pne imovine }\end{array}$ & $\begin{array}{c}\text { Multiplika- } \\
\text { tor sopstvenog } \\
\text { kapitala }\end{array}$ & g \\
\cline { 2 - 8 } & $(1)$ & $(2)=\left(3^{*} 4^{\star} 5\right)$ & $(3)$ & $(4)$ & $(5)$ & $(6)=\left(1^{\star} 2\right)$ \\
\hline Alfa plam, Vranje & 0,55 & 7,27 & 9,82 & 0,65 & 1,15 & 4,00 \\
\hline Bambi, Požarevac & 0,80 & 33,69 & 18,86 & 1,10 & 1,63 & 26,95 \\
\hline Goša FOM, Smed. Palanka & 1,00 & 0,58 & 0,35 & 0,85 & 1,94 & 0,58 \\
\hline Imlek, Beograd & 0,49 & 22,09 & 10,87 & 0,78 & 2,61 & 10,82 \\
\hline Impol Seval, Sevojno & 0,89 & 9,82 & 2,33 & 1,34 & 3,14 & 8,74 \\
\hline Milan Blagojević, Smederevo & 1,00 & 22,94 & 17,39 & 1,00 & 1,32 & 22,94 \\
\hline Neoplanta, Novi Sad & 1,00 & 3,61 & 3,53 & 0,78 & 1,31 & 3,61 \\
\hline Žitobanat, Vršac & 0,62 & 6,07 & 2,54 & 1,84 & 1,30 & 3,76 \\
\hline
\end{tabular}

Izvor: Prikaz autora na osnovu podataka iz www.belex.rs 
Tabela 5. Realne SGR hotelskih i ugostiteljskih preduzeća u 2012. godini

\begin{tabular}{lccc}
\hline \multicolumn{1}{c}{ Preduzeće } & $\begin{array}{c}\text { g-održiva } \\
\text { stopa rasta }\end{array}$ & $\begin{array}{c}\text { stopa } \\
\text { inflacije }\end{array}$ & $\begin{array}{c}\text { realna } \\
\text { održiva } \\
\text { stopa rasta }\end{array}$ \\
\hline Astoria, Beograd & 0,14 & 12,2 & $-12,06$ \\
\hline Excelsior, Beograd & 0,70 & 12,2 & $-11,50$ \\
\hline Palisad, Zlatibor & 2,29 & 12,2 & $-9,91$ \\
\hline Tisa, Senta & 0,15 & 12,2 & $-12,05$ \\
\hline Avala, Požarevac & 38,08 & 12,2 & 25,88 \\
\hline Golubački grad, Golubac & 1,22 & 12,2 & $-10,98$ \\
\hline Madera, Beograd & 4,78 & 12,2 & $-7,42$ \\
\hline Pomoravlje, Beograd & 1,15 & 12,2 & $-11,05$ \\
\hline
\end{tabular}

Izvor: Prikaz autora

Tabela 6. Ralne SGR hotelskih i ugostiteljskih preduzeća u 2013. godini

\begin{tabular}{lccc}
\hline \multicolumn{1}{c}{ Preduzeće } & $\begin{array}{r}\text { g-održiva } \\
\text { stopa rasta }\end{array}$ & $\begin{array}{c}\text { stopa } \\
\text { inflacije }\end{array}$ & $\begin{array}{c}\text { realna } \\
\text { održiva } \\
\text { stopa rasta }\end{array}$ \\
\hline Astoria, Beograd & 2,47 & 2,2 & 0,27 \\
\hline Excelsior, Beograd & 3,75 & 2,2 & 1,55 \\
\hline Palisad, Zlatibor & 0,19 & 2,2 & $-2,01$ \\
\hline Tisa, Senta & 2,79 & 2,2 & 0,59 \\
\hline Avala, Požarevac & 17,77 & 2,2 & 15,57 \\
\hline Golubački grad, Golubac & 1,83 & 2,2 & $-0,37$ \\
\hline Madera, Beograd & 2,98 & 2,2 & 0,78 \\
\hline Pomoravlje, Beograd & 0,03 & 2,2 & $-2,17$ \\
\hline
\end{tabular}

Izvor: Prikaz autora

Sasvim drugačija situacija je zabeležena kod prerađivačkih preduzeća (tabele 7 i 8 ) kod kojih je 5 preduzeća u 2012. godini zabeležilo pozitivnu realnu održivu stopu rasta, a samo 3 negativnu, a u 2013. godini, čak 7 preduzeća pozitivnu, a samo jedno negativnu realnu održivu stopu rasta, zahvaljujući prvenstveno zavidnoj visini nominalnih održivih stopa rasta, proisteklih iz značajnih nivoa profitnih stopa. Otuda proizilazi konstatacija da prerađivačka preduzeća poseduju znatno veći realni potencijal za rast od hotelskih i ugostiteljskih preduzeća.

Tabela 7. Realne SGR prerađivačkih preduzeća u 2012. godini

\begin{tabular}{lccc}
\hline \multicolumn{1}{c}{ Preduzeće } & $\begin{array}{c}\text { g-održiva } \\
\text { stopa rasta }\end{array}$ & $\begin{array}{c}\text { stopa } \\
\text { inflacije }\end{array}$ & $\begin{array}{c}\text { realna } \\
\text { održiva } \\
\text { stopa rasta }\end{array}$ \\
\hline Alfa plam, Vranje & 20,53 & 12,2 & 8,33 \\
\hline Bambi, Požarevac & 20,70 & 12,2 & 8,50 \\
\hline $\begin{array}{l}\text { Goša FOM, } \\
\text { Smed. Palanka }\end{array}$ & 3,52 & 12,2 & $-8,68$ \\
\hline Imlek, Beograd & 20,92 & 12,2 & 8,72 \\
\hline Impol Seval, Sevojno & 14,95 & 12,2 & 2,75 \\
\hline $\begin{array}{l}\text { Milan Blagojević, } \\
\text { Smederevo }\end{array}$ & 36,08 & 12,2 & 23,88 \\
\hline Neoplanta, Novi Sad & 8,84 & 12,2 & $-3,36$ \\
\hline Žitobanat, Vršac & 4,25 & 12,2 & $-7,95$ \\
\hline
\end{tabular}

Izvor: Prikaz autora
Tabela 8. Realne SGR prerađivačkih preduzeća u 2013. godini

\begin{tabular}{lccc}
\hline \multicolumn{1}{c}{ Preduzeće } & $\begin{array}{c}\text { g- održiva } \\
\text { stopa rasta }\end{array}$ & $\begin{array}{c}\text { stopa } \\
\text { inflacije }\end{array}$ & $\begin{array}{c}\text { realna } \\
\text { održiva } \\
\text { stopa rasta }\end{array}$ \\
\hline Alfa plam, Vranje & 4,00 & 2,2 & 1,80 \\
\hline Bambi, Požarevac & 26,95 & 2,2 & 24,75 \\
\hline $\begin{array}{l}\text { Goša FOM, } \\
\text { Smed. Palanka }\end{array}$ & 0,58 & 2,2 & $-1,62$ \\
\hline Imlek, Beograd & 10,82 & 2,2 & 8,62 \\
\hline Impol Seval, Sevojno & 8,74 & 2,2 & 6,54 \\
\hline $\begin{array}{l}\text { Milan Blagojević, } \\
\text { Smederevo }\end{array}$ & 22,94 & 2,2 & 20,74 \\
\hline Neoplanta, Novi Sad & 3,61 & 2,2 & 1,41 \\
\hline Žitobanat, Vršac & 3,76 & 2,2 & 1,56 \\
\hline
\end{tabular}

Izvor: Prikaz autora

\section{REZIME}

Sprovedenim istraživanjem postavljene hipoteze su delom potvrđene, a delom opovrgnute. $\mathrm{H} 1$ je opovrgnuta jer je dokazano da postoji značajna razlika između održive stope rasta hotelskih i ugostiteljskih preduzeća, sa jedne strane, i prerađivačkih preduzeća sa druge strane. $\mathrm{H} 2$ je potvrđena u smislu da ne postoji značajna razlika između održive stope rasta hotelskih, ugostiteljskih i prerađivačkih preduzeća u celini u 2013. godini u odnosu na 2012. godinu, iako razlika postoji kod manjeg broja pojedinačnih preduzeća. H3 je opovrgnuta jer je utvrđeno da postoji značajna razlika između održive stope rasta i stope inflacije u 2012. godini i da je prvenstveno kod hotelskih i ugostiteljskih preduzeća stopa inflacije znatno nadmašivala njihovu održivu stopu rasta. $\mathrm{H} 4$ je delimično potvrđena u odnosu na hotelska i ugostiteljska preduzeća čija je održiva stopa rasta približno bila na nivou inflacije u 2013. godini, ali je opovrgnuta u odnosu na prerađivačka preduzeća čija je održiva stopa rasta znatno premašivala stopu inflacije u 2013. godini.

Obzirom na geografski položaj, prirodne karakteristike i povoljne klimatske uslove, hotelska i ugostiteljska preduzeća u Srbiji kao sastavni deo turističke industrije zemlje imaju značajan razvojni potencijal i predispozicije da postanu važan segment razvoja ekonomije čitave zemlje. Zbog toga bi se moglo očekivati da preduzeća ovog sektora imaju značajnu održivu stopa rasta. Međutim, u poređenju sa različitim preduzećima prerađivačke industrije, pokazalo se da hotelska i ugostiteljska preduzeća znatno zaostaju u tom pogledu. Pored niske profitabilnosti kao specifičnosti ove privredne grane, za koju su odgovorna sama hotelska i ugostiteljska preduzeća kao i okruženje i uslovi u kojima posluju, tu su i makroekonomski faktori koji podjednako (negativno ili pozitivno) utiču na sve privredne grane. Ovde se prvenstveno misli na makroekonomsku stabilnost koja se iskazuje kroz cenovnu stabilnost odnosno stopu inflacije. Pokazalo se da je u posmatranim godinama veći uticaj na visinu realne održive stope rasta preduzeća iz analiziranih privrednih grana imala visina stope inflacije koja uvek preti da obezvredi postignuti nominalni rezultat, nego što je imao sam njihov ostvareni poslovni uspeh i finansijski rezultat. Niska održiva stopa rasta hotelskih i ugostiteljskih preduzeća u Srbiji označava njihov nizak potencijal za samostalni rast bez dodatnih zaduživanja, a ubrzani rast ovih preduzeća preko održive stope rasta uz dodatna ili čak pre- 
komerna zaduživanja, može ovim preduzećima stvoriti likvidnosne probleme, a u težim slučajevima, čak ih uvesti i u bankrotstvo. Ista opasnost preti ovim preduzećima ukoliko odustanu od rasta i ne iskoriste ni nivo održive stope rasta, jer ih to vodi u stagnaciju, gubitak postojeće tržišne pozicije, a u krajnjem slučaju takođe ih može voditi u bankrotstvo.

Za dalji ubrzaniji razvoj hotelskih i ugostiteljskih preduzeća u Srbiji, interno je potrebno stalno unapređivati efikasnost i profitabilnost ovih preduzeća na mikro nivou, dok je eksterno na makro nivou potreban napor države da obezbedi stabilne, zdrave uslove poslovanja, a posebno da održi cenovnu stabilnost tj. nisku stopu inflacije i da osmisli adekvatne stimulativne mere za podsticanje rasta i razvoja preduzeća iz ove delatnosti i obezbedi pristup jeftinijim i namenskim, specijalizovanim izvorima finansiranja i zaduživanja.

Sprovedeno istraživanje može da posluži kao osnova za dalja istraživanja na ovu temu i različita komparativna sagledavanja realnih potencijala rasta grupa delatnosti unutar turističke grane privrede.

\section{LITERATURA}

Beogradska berza. (2012-2013). Održive stope rasta uzorkovanih preduzeća. Preuzeto 12. juna 2015. sa htp://www. belex.rs/

Braley, R., \& Myers, S. (2003). Principles of Corporate Finance. New York: McGraw-Hill.

Chen, H.Y., Gupta, M.C., Lee, A.C., \& Lee, C.F. (2013). Sustainable growth rate, optimal growth rate, and optimal payout ratio: A joint optimization approach. Journal of Banking \& Finance, 37 (4), 1205-1222.

Clouse, M., \& McFaddin, S. (1994). Sustainable growth in the US gas utility industry. Resources Policy, 20 (2), 117-123.

Higgins, R.C. (1977). How Much Growth Can a Firm Afford? Financial Management, 6 (3), 7-16.

Higgins, R.C. (1981). Sustainable Growth Under Inflation. Financial Management, 10 (4), 36-40.

Ministarstvo finansija. (2014). Osnovni indikatori makroekonomskih kretanja. Preuzeto 12. juna 2015. sa htpp:// www.mfin.gov.rs/

Stowe, J. (2000). Analysis of Equity Investments. Boston: Association for Investment Management and Research.

\section{SUSTAINABLE GROWTH RATE OF HOTEL AND CATERING ENTERPRISES IN SERBIA}

\begin{abstract}
:
All profitable enterprises, including the hotel and catering companies, may get into financial difficulties and even bankruptcy if they grow slower or faster than expected. The assessment of extremely slow or rapid growth of hotel and catering businesses is achieved through comparison with their sustainable growth rate. The sustainable growth rate is the maximum growth rate a company can achieve without additional borrowing. The aim of this study is to determine the sustainable growth rate for individual hotel and catering enterprises in Serbia in 2012 and 2013 and determine whether there are differences between this sector and other industry sectors in Serbia concerning this issue. In addition, the study seeks to establish a realistic sustainable growth rate of hotel and catering enterprises in Serbia by taking into account the current inflation rate in the observed years, as well as to clarify the causes of discrepancy between nominal and real sustainable growth rates. The identified real sustainable growth rates of analyzed hotel and catering enterprises in Serbia serve as a landmark in drawing conclusions about the development potential of these enterprises and provide support in finding the appropriate internal and external incentives needed for further growth of these companies.
\end{abstract}

\section{Key words:}

sustainable growth rate, hotel and catering enterprises, the dividend policy. 